\title{
It Takes a Village: Investigating the Critical Role Clinical Faculty Play in Mathematics Teacher Education
}

\author{
Damon L. Bahr \\ damon_bahr@byu.edu
}

Follow this and additional works at: https://scholarsarchive.byu.edu/facpub

Part of the Teacher Education and Professional Development Commons

\section{Original Publication Citation}

Bahr, D.L. (211). It takes a village: Investigating the critical role clinical faculty play in mathematics teacher education. Journal of Mathematics Teacher Education.

http://www.springerlink.com/content/1386-4416

\section{BYU ScholarsArchive Citation}

Bahr, Damon L., "It Takes a Village: Investigating the Critical Role Clinical Faculty Play in Mathematics Teacher Education" (2013). Faculty Publications. 815.

https://scholarsarchive.byu.edu/facpub/815 


\author{
It Takes a Village: \\ Investigating the Critical Role Clinical Faculty Play \\ in Mathematics Teacher Education
}

Date of submission: September 6, 2011

Damon L. Bahr

Brigham Young University

201-F MCKB

Provo, Utah 84602

Business: 801-422-6114

Home: 801-224-5528

Fax: 801-422-0652

damon_bahr@byu.edu 
It Takes a Village

\begin{abstract}
The dispositions of preservice elementary education teachers toward reformoriented mathematics education were surveyed before and after an extended pre-student teaching practicum. During the practicum, university and school-based personnel served a "clinical faculty" as they supported the preservice teachers' practicum experiences. The preservice teachers' perceptions of the clinical faculty's dispositions were also surveyed. Relationships between changes in the dispositions of the preservice teachers and their perceptions of the clinical faculty were discovered thus highlighting the important influence clinical faculty wield as mathematics teacher educators.
\end{abstract}


It Takes a Village

\author{
It Takes a Village: \\ Investigating the Critical Role Clinical Faculty Play \\ in Mathematics Teacher Education
}

The purpose of this study is to examine the influence of clinical faculty in the developing dispositions of preservice teachers towards reform-based mathematics teaching and learning. Specifically, we studied the relationship between the dispositions of two groups: (a) preservice elementary teachers involved in field-based practica, and (b) clinical faculty, who support these preservice students' practica experiences. The preservice teachers and clinical faculty involved in the study were all associated with the elementary education program at Brigham Young University.

The current reform movement in mathematics education encourages significant paradigmatic change. Indeed, as Wood and Turner-Vorbeck (2001) write, "change in the practice of teaching mathematics will require more than simply minor adjustments in current ways of teaching" (p. 185). Such changes involve learning to teach "mathematics in ways that honor and are rooted in concerns for the integrity of mathematics as a discipline and that attend to and make serious use of students' thinking” (Ball, 2001, p. 11). McNeal (2001) has "repeatedly observed that beginning teachers who seem determined to focus on children's mathematics find this difficult to do under the pressures of practical concerns such as proficiency tests, expectations of parents, colleagues, administrators, evaluations, and scheduling" (p. 209).

If it takes a village to raise a child (Cowen-Fletcher, 1994), preparing a mathematics teacher may require a similar supporting cast, especially in the current era of reform. The mathematical preparation of preservice elementary teachers is generally 
It Takes a Village

supported by university content and methods faculty and by various types of clinical faculty who often serve as "boundary spanners" (Sandholtz \& Finan, 1998, p. 24) between the theories of university course work and the practice of the elementary classroom. Indeed, it is not uncommon for clinical faculty to be selected from the ranks of inservice teachers. We argue both university and clinical faculty are legitimate mathematics teacher educators. We further argue that in order for this supporting cast to be termed a "village," there must be a synchrony of purpose and philosophy among them, a "conceptual interweaving" (Author et al., 2011) between the theory espoused by university faculty and the practice espoused by clinical faculty. Darling-Hammond (2000) writes, "Recent evidence also indicates that reforms of teacher education creating more tightly integrated programs with extended clinical preparation interwoven with coursework on learning and teaching produce teachers who are ... more effective" (pp. 166-177). She further argues (2001), [Such programs promote] "the application of theoretical principles to problems in specific contexts while appropriately complicating efforts to draw generalizations about practice" (p. 171).

Writing about the need for changes in teacher education, Feiman-Nemser (2001) indicates teacher education programs frequently fail to adequately address the "influence of . . on-the-job experience" (p. 1014) upon the novice's developing dispositions.

Guyton and McIntrye (1990) add that field experiences are often “.. . developed out of convenience or tradition" (p. 517), and Darling-Hammond (2009) writes, "Often, the clinical side of teacher education has been fairly haphazard, depending on the idiosyncrasies of loosely selected placements with little guidance about what happens in them and little connection to university work" (p. 11). Zeichner (2010) agrees, “. . one 
It Takes a Village

of the central problems that has plagued college-and university-based preservice teacher education for many years (is the) disconnect between the campus and school-based components of programs" (p. 89). If clinical faculty are indeed "boundary spanners,"(Sandholtz \& Finan, 1998, p. 24) then they could play a critical connecting role.

The connecting role clinical faculty can play is not necessarily a new idea. Conant (1963) elaborated on clinical faculty preparation by suggesting that they be educated to understand the implications of "expert judgment" in "concrete teaching situations" (p. 140). Cornbleth \& Ellsworth (1994) suggest that Conant's “clinical professor" was to be a conduit for specialists' advice "expert judgment." The value of teachers' craft or experiential knowledge is acknowledged implicitly if at all. The assumption is that knowledge generated by "scientific" research and interpreted by experts (presumably university faculty-researchers) is to be applied rather directly in practice and, further, that such knowledge can be transmitted from experienced to prospective teachers (p. 58)... [if clinical faculty are themselves engaged in the] acquisitions and application of university knowledge. (p. 66).

Unsurprisingly, Vacc \& Bright (1999) found the ability of preservice teachers to incorporate reform-based beliefs and pedagogy depended on the level of coherence between the philosophies associated with preservice methods instruction and clinical experience. They concluded,

The framework underlying the content presented in mathematics methods courses needs to be consistent with the framework of the mathematics education program that preservice teachers observe and implement during field experiences. If the 
It Takes a Village

two frameworks are in conflict, the theories and concepts presented during the mathematics methods course may not seem plausible and may be rejected (p. 91). Hollingsworth (1989) found that preservice teachers who make the greatest professional growth were those placed with one type of clinical faculty, cooperating teachers, who encouraged them to apply what they learned in methods courses.

Like Vacc \& Bright (1999), we have observed the influence one type of clinical faculty, cooperating teachers, can have upon preservice teacher candidates during an elementary mathematics methods course practicum, particularly when there is a high degree of synchrony between the philosophies that underlie the methods course and the pedagogy of the cooperating teacher (Author et al., 2011). Because of the potential they possess to be "boundary spanners" (Sandholtz, J.H. and Finan, E.C., 1998, p. 24), we argue that other types of clinical faculty can also play a crucial role in bridging the theory-practice gap. Indeed, if preservice teachers are educated by a village of reformminded teacher educators, those preservice teachers would tend to be disposed towards a favorable view of the current mathematics education reforms and apt to engage in reform-based practice.

\section{Context and Research Questions}

Three types of clinical faculty roles have evolved in Brigham Young University's elementary teacher preparation program (Bullough, Draper, Smith, \& Birrell, 2004). The first is the traditional cooperating, or "Mentor Teacher," in whose classroom student teachers and/or pre-student teachers engage in field experience. The second are Partnership Facilitators (PF) who "supervise and mentor interns who, in lieu of student teaching, teach in a school full time for half-pay and full benefits. Two interns each 
It Takes a Village

filling a single teacher position allows for the release of a master teacher, the PF, to serve as an on-site teacher educator" (p. 506) who also assist student teachers and pre-student teachers. Thirdly, "Clinical Faculty Associates (CFAs), . . [who] are highly respected teachers, often who have served previously as PFs, ... are employed by the University for 2-year appointments to work full time within the Teacher Education Department. . . . and are deeply involved with the PFs, interns, cooperating and student teachers" (p. 506).

Preservice teachers at BYU experience a methods semester just prior to student teaching or interning in which they take course work in both general and disciplinespecific teaching methods, including mathematics. For four weeks toward the end of this semester, course work is suspended while the preservice teachers spend all day in a public school classroom assisting the inservice teacher, teaching small and large groups, and completing various methods course assignments. MTs, PFs, and CFAs provide the primary support for this practicum experience, with limited or minimal support being provided by the methods instructors. The preservice teachers return to campus for two more weeks of course work and a final exam after the practicum.

We examined the dispositions preservice teachers develop as they attempt to connect the theory they learn in mathematics methods courses and the practice they observe and implement in their methods-related field practica (Sumara and Luce-Kapler, 1996) and the role of clinical faculty in this process. Specifically, we make inferences about disposition development in the context of addressing the following questions.

1. How and to what extent did the dispositions of the preservice teachers towards reform-based mathematics teaching and learning change during the methods-related field practicum? 
It Takes a Village

2. What is the relationship between changes in the dispositions of preservice teachers involved in the practicum and their perceptions of the dispositions of clinical faculty who supervise their practica experiences?

The role of interpersonal factors play in mentoring relationships has long been a topic of study (e.g., Hargreaves, A. \& Fullan, M., 2000). Because the nature of preservice teacher-clinical faculty relationships could affect observations associated with the second research question, we ask

3. What is the relationship between the nature of the rapport between preservice teachers and mentor teachers and changes in the dispositions of those preservice teachers towards reform-based mathematics teaching and learning? If significant relationships are discovered between changes in the dispositions of the preservice teachers and each of the clinical faculty who supervise them-MTs, PFs, and CFAs - we will also examine the "village" question. That is, we will address this question about the collective effects of a conceptual synchrony among clinical faculty.

4. How do the dispositional changes of preservice teachers who are supervised by clinical faculty that all possess a reform perspective—a "village" — compare to the dispositional changes of preservice teachers who are supervised by one or more clinical faculty who do not possess a reform perspective?

We hypothesize that the dispositions of preservice teachers toward reform-based mathematics instruction are highly influenced by their perceptions of the dispositions of all three clinical faculty who support their mathematical field practicum experiences and that there is a collective effect when all three are perceived to possess a reform 
It Takes a Village

perspective. We further hypothesize that there are important interpersonal factors that mediate this influence.

Methods

Design

We employed a survey research design (McMillan \& Schumacher, 2001) because of our intention to gather data about the variables of concern to our study, the dispositions of our subjects relative to mathematical reform, via a survey. This same design allowed us to group respondents by their responses to survey items and thus investigate relationships among the data.

Subjects

The subjects for this study were preservice teachers enrolled in one of five sections of either an elementary or early childhood education mathematics methods course and an accompanying public school practicum course, in the setting described previously. The lead researcher served as instructor for three of those sections. There were 99 preservice teachers enrolled in these courses who were potential subjects. All were invited, but not coerced, to participate in data collection, and all 99 agreed. Instruments

To assess perspectives of the large number of preservice teachers involved in the methods course and associated practicum, we developed a selected-response survey consisting of six sections and administered it after the practicum concluded. The items in the first five sections included six bi-directional response categories, and the items in the final section included five uni-directional response categories. A copy of the survey appears in the appendix. The first section consisted of a 20 -item survey developed by 
It Takes a Village

Ross, McDougall, Hogaboam-Gray, and LeSage (2003), designed to assess respondents dispositions towards nine characteristics, or dimensions, of reform-based teaching. Results obtained from this survey have been shown to correlate highly with observations of actual classroom practice, and the dimensions appear in Table 1. Preservice teachers were asked to respond to these items reflecting their dispositions at the end of the practicum.

The next section consisted of the same set of items, and the preservice teachers were asked to respond to them retrospectively, as if they were responding to them prior to the practicum. Cantrell (2003) demonstrated the validity of retrospective pre-measures in assessing the dispositions of preservice students. Retrospective measures address the problem of response-shift bias (Aiken \& West, 1990; Cronbach \& Furby, 1970), and as a result, tend to produce gain scores with greater validity and greater statistical power (Bray, Maxwell, \& Howard, 1984; Howard et al., 1979).

In the third, fourth, and fifth sections, the survey assessed preservice teachers' perceptions of their clinical faculties' dispositions-MTs, PFs, and CFAs - regarding the same nine dimensions about which they themselves were surveyed. Because of concerns about overall survey length, we created one item for each dimension rather than using the items from the Ross et al. survey. Three procedures were used to establish both the reliability and validity of the responses and interpretations obtained from these items. These items were examined by Ross and found to represent the intent of the survey's dimensions (personal communication, April 24, 2007). In a previous study (Author et al., 2010), we invited 10 former preservice teachers to read and interpret the survey items aloud in order to assess the degree to which the items were being interpreted according to 
It Takes a Village

our intentions, an issue of validity. Items were adjusted according the feedback this procedure provided. We also found in that study a high degree of clustering among the responses to these nine items by using item-to-adjusted total correlation (Item-Total Correlation, SPSS, 2008), obtaining a Cronbach's alpha of .952.

The final section consisted of six items relating to preservice-mentor teacher rapport that we have also used and validated elsewhere using the same procedures as described above (Author et al., 2011). We deliberately did not address interpersonal variables involving the other clinical faculty because of concerns about survey length. We assumed that if interpersonal relationships between preservice teachers and mentor teachers affected changes in the dispositions of those preservice teachers, it would be safe to generalize similar relationships between preservice teachers and other clinical faculty would also affect PST dispositional changes. Table 2 summarizes the contents of the survey by section.

Because one of us was also the methods instructor of a substantial portion of the preservice teachers, the potential for response bias was dealt with in two ways. First, the surveys were completed at the end of the semester when most of the preservice teachers' grades had been determined. Second, we demonstrated that there was a high degree of correlation among items within the same section as described previously (McMillan \& Schumacher, 2001).

\section{Analysis}

All statistical analyses were performed using SPSS (2008). Responses to the items within each section were averaged to obtain overall measures of the perceptions associated with those sections for each subject. Additional descriptive statistics were also 
It Takes a Village

computed for these variables. A t-test was performed to test for the presence of a significant difference between subjects' dispositions about reform mathematics before and after the practicum. A ratio was computed between the pre-post difference and the pooled standard deviation of the pre and post response distributions in order to determine effect size. (Ellis, 2010).

Subject responses related to each of the other sections, their perceptions of the clinical faculty and of the level of support provided specifically by the MTs, were used to divide subjects into two groups using the median response as the separator between the two groups. Then the overall post-practicum variable means, survey section 1, for the two groups were compared using analysis of covariance procedures with the means on the overall pre-practicum variable as a co-variant. For example, the median for responses about the PST's perception of the dispositions of their mentor teachers was 4.27. PST's were placed in two groups according to whether their responses were above or below that median then their overall response means on the post-practicum variable were compared. Thus for this analysis these varied groupings according to potential factors constituted independent variables and were used in analyses of covariance with the post-practicum overall variable as the dependent variable and the pre-practicum overall variable as the covariant.

These groupings were used to make second-tier groups to test the "village" hypothesis, as mentioned previously. Preservice teachers whose responses regarding the three clinical faculty and the level of mentor teacher rapport placed them in the "above median" groups in each separate analysis were placed in a group and their overall postpracticum means were compared to all other teachers' post-practicum means using 
It Takes a Village

similar analysis of covariance procedures.

Inasmuch as we were interested in the preservice teachers' perceptions of clinical faculty dispositions, it is possible that the preservice teachers' own dispositions toward reform mathematics education may have colored their perceptions of clinical faculty. To investigate this potential issue, Pearson r correlations were computed between the overall variables obtained from their responses to the pre- and post-practicum survey items and the items measuring their perceptions of the clinical faculty.

\section{Results}

As shown in Table 3, there was a wide range in the subjects' responses on the premeasure. The overall mean was 4.22. The responses varied from 2.30 to 5.50, a range of 3.20, with a standard deviation of .62. Thus, about two-thirds of the subjects' responses were hovering below the "agree" response category and above the "disagree somewhat" category. The mean responses of 15 of the subjects were at or below the theoretical median of 3.5, the median point of the survey scale. Only eight mean responses were at or above 5 on the scale.

Responses on the post-measure averaged 4.78. The difference between pre and post means was statistically significant with an effect size of 1.238 pooled standard deviations, which is quite large. The range of responses on the post measure was much smaller than the range on the pre-measure - 3.85 to 5.70 - with maximum and minimum responses that were higher than the maximum and minimums on the pre-measure. No subject responses were below the theoretical mean and only one response was below 4.0 on the scale. 24 responses were at or above 5 on the scale. 87 PSTs showed a gain from 
It Takes a Village

to post, $59(56 \%)$ showed a gain of at least one standard deviation, and $72(69 \%)$ showed a gain of at least $1 / 2 \mathrm{SD}$.

As explained previously, subject responses related to their perceptions of the MTs, CFAs, PFs, and of the level of support provided specifically by the MTs were used to divide subjects into two groups for each of five separate analyses of covariance using the post-practicum measure as the dependent variable and the pre-measure as a covariate. This division was accomplished by determining the median response of the perceptions related to one set of perceptions-MT, CFA, etc.- - then placing those subjects whose responses were above the median in one group and subjects whose responses were below the median in the second group, resulting in two roughly equal-sized groups for each analysis. Descriptive statistics for PSTs' perceptions of clinical faculty appear in Table 4, and the analysis of covariance results appear in Table 5.

Table 4 depicts a wide variation in the responses of PSTs, as shown in both the range of responses and the standard deviations. The means, with one exception, are near the "agree somewhat" response category. The SDs approximate the gap between response categories on the survey.

As shown in Table 5, responses of subjects in the above-median group on the post-measure were significantly greater than those whose perceptions were below the median when the groupings were based upon perceptions of MTs, PFs, and upon the degree of MT support and when the pre-measure was taken into account. The difference between groups approached significance when the grouping was based upon perceptions of CFAs.

To test the "village" hypothesis, as mentioned previously, preservice teachers 
It Takes a Village

whose responses regarding the three clinical faculty and the level of mentor teacher rapport placed them in the "above median" groups in each separate analysis were placed in a group and their overall post-practicum means were compared to all other teachers' post-practicum means using analysis of covariance procedures. Results displayed in Table 6 show a significant difference favoring the group whose perceptions of clinical faculty were all above the respective medians.

We were concerned with the possibility that the preservice teachers' own dispositions toward reform mathematics education may have colored their perceptions of the dispositions of clinical faculty. Therefore, Pearson $r$ correlations were computed between the overall variables obtained from their responses to the pre- and postpracticum survey items and the items measuring their perceptions of the clinical faculty and MT support. If their own dispositions influenced their perceptions, we conjecture meaningful correlations would have been obtained. Table 7 clearly displays an absence of such correlations between either pre- or post-measured dispositions and those perceptions.

\section{Discussion and Conclusions}

Near the end of the methods course, but prior to the practicum, there was a wide range in the dispositions of the preservice teachers towards reform mathematics. Overall, the analysis suggests that the PSTs' responses hovered in the zone of ambiguity on the survey scale, the middle portion. At best, we might be able to say there was a mild disposition favoring a reform perspective among them.

There was a dramatic change in PSTs' dispositions as revealed by the post measure that was both statistically significant and substantive. This represents a 
It Takes a Village

meaningful change in PST disposition towards a reform mathematics perspective.

Something happened during the practicum to affect this change, and the following paragraphs provide evidence for the role of clinical faculty in influencing the change.

The logic underlying our investigation of the relationship between the dispositions towards reform-based mathematics teaching and learning of preservice teachers involved in field-based practica and the dispositions of the clinical faculty who supervised them stems from the wide variability of the dispositions of the latter. This wide variability in dispositions, at least as perceived by the preservice teachers, allowed us to create groups of preservice teachers distinguished by the dispositions of the clinical faculty with whom they worked. Those preservice teachers who worked with clinical faculty that were perceived to be more reform minded, experienced a greater change in dispositions favorable to mathematical reform than those whose supportive clinical faculty were less favorable. This result harmonizes with those obtained by Vacc \& Bright (1999) who found the ability of preservice teachers to incorporate reform-based beliefs and pedagogy depended on the level of coherence between the philosophies associated with preservice instruction and classroom practice. The current study extends their conclusions to all potential clinical faculty, particularly if those faculty are school practitioners basing their clinical support upon their own classroom practice.

Because of the potential effect interpersonal factors can have upon mentoring and mentoring relationships (Hargreaves, A. \& Fullan, M., 2000), we also investigated the extent to which interpersonal relationships between preservice teachers and mentor teachers influenced changes in the dispositions of those preservice teachers towards reform-based mathematics education. Those preservice teachers who evidenced 
It Takes a Village

meaningful personal relationships with their MTs experienced a greater change in dispositions favorable to mathematical reform than those who did not. Survey length precluded measuring data about relationships with other clinical faculty and conducting similar analyses, but we conjecture the nature of relationships between preservice teachers and other clinical faculty would also affect preservice teacher dispositional changes.

The collective influence of clinical faculty who all possess a reform perspective and who develop supportive relationships with the preservice teachers they supervise creates a "village," a supporting cast who speak with one voice about the nature of mathematics teaching and learning. On the contrary, preservice students face a significant challenge as they develop their own sense of personal identity as teachers while attempting to connect the theory they learn in mathematics methods courses and the practice they observe and implement in their field practica. Because this challenge often includes reconciling incongruous theories and practices, they are faced with reconciling disparate images of themselves as teachers. (Sumara and Luce-Kapler, 1996).

Developing teacher identity involves utilizing particular discourses that characterize the teacher role as novices try on different teacher costumes (Gee, 1999, 2001). Discourses act as "identity kits," complete with the "appropriate costume and instructions on how to act, talk, and often write, so as to take on a particular role that others will recognize" (Gee, 2001, p. 526). Therefore, Hall (2000, p. xi) uses the word "situational" and Bullough (1991, p. 47) uses "chameleon" in describing the changing identities of novices.

When mathematics teacher educators answer the challenge of mathematics 
It Takes a Village

teaching reform by focusing their preservice teacher preparation efforts on school classrooms, they are faced with a daunting obstacle-helping preservice teachers negotiate the conflict between the separate identities that can result from disconnected university and school experiences (Sumara \& Luce-Kapler, 1996). Thus Feiman-Nemser (2001) described teacher identity development as a "complex, on-going process" in which novices "must consolidate a professional identity" as they "struggle to reconcile competing images of their role" (p. 1029).

A disparity between the methods espoused in school classrooms by clinical faculty and those espoused in university courses often limits the influence of university teacher educators (Eisenhart, Borko, Underhill, Brown, Jones, \& Agard, 1993; Tabachnick, Popkewitz, \& Zeichner, 1979-1980). Thus a mismatch between what they are learning in their courses and what they are taught by clinical faculty may present preservice teachers with conflicting teacher identities with which to identify. Bullough and Knowles (1991) note when the novice teacher's sense of identity is not well defined, methods course knowledge is superficial and easily replaced by the practices espoused by clinical faculty.

On the other hand, if a coherent image of mathematics teaching and learning is portrayed by university instructors and clinical faculty, the "shape-shifters" or "chameleons" do not have to radically adjust to vastly differing professional expectations. Thus, the fragile preservice teacher identities favoring a reform perspective developed during university coursework can be enhanced and solidified, rather than replaced, during field experiences. 
It Takes a Village

Liping Ma (1999) placed responsibility for moving forward the current reform movement squarely upon the shoulders of preservice teacher educators. The fulfillment of that responsibility is more likely to occur if "villages" of university and clinical faculty synchronously encourage similar dispositions toward mathematics, the learning of mathematics, and the teaching of mathematics, a condition that will result when there is a seamless interweaving between the theories of the university and the practice of clinical experience. Indeed, helping all students to reach their mathematical potential will be a more realistic possibility if all the teacher educators within a village envisioned the ideal classroom to look something like this depiction from the NCTM (2000).

Imagine a classroom, a school, or a school district where all students have access to high-quality, engaging mathematics instruction. There are ambitious expectations for all, with accommodation for those who need it. ... The curriculum is mathematically rich, offering students opportunities to learn important mathematical concepts and procedures with understanding. . . . Teachers help students make, refine, and explore conjectures on the basis of evidence and use a variety of reasoning and proof techniques to confirm or disprove those conjectures. Students are flexible and resourceful problem solvers. Alone or in groups and with access to technology, they work productively and reflectively, with the skilled guidance of their teachers. Orally and in writing, students communicate their ideas and results effectively. They value mathematics and engage actively in learning it (p. 3). 
It Takes a Village

\section{References}

Aiken, L. S., \& West, S. G. (1990). Invalidity of true experiments: Self-report pretest bias. Evaluation Review, 14(4), 374-390.

Author et al., 2010 [details removed for peer review]

Author et al., 2011 [details removed for peer review]

Ball, D. L. (2001). Teaching, with respect to mathematics and students. In T. Wood, B. S. Nelson, \& J. Warfield (Eds.), Beyond classical pedagogy: Teaching elementary school mathematics (pp. 11-22). Mahwah, NJ: Lawrence Erlbaum.

Bray, J. H., Maxwell, S. E., \& Howard, G. S. (1984). Methods of analysis with response shift bias. Educational and Psychological Measurement, 44, 781-804.

Bullough, R.V. (1991). Exploring personal teaching metaphors in preservice teacher education. Journal of Teacher Education, 42(1), 43-51.

Bullough, R. V., Jr., Draper, R. J., Smith, L., \& Birrell, J. R. (2004). Moving beyond collusion: clinical faculty and university/public school partnership. Teaching and Teacher Education, 20(6), 505-521.

Bullough, R. V., \& Knowles, J. (1991). Teaching and nurturing: Changing conceptions of self as teacher in a case study of becoming a teacher. Qualitative Studies in Education, 4(2), 121-140.

Cantrell, P. (2003). Traditional vs. retrospective pretests for measuring science teaching efficacy beliefs in preservice teachers. School Science and Mathematics, 103(4), $177-185$.

Conant, J. B. (1963). The Education of American Teachers. New York City, NY: McGraw-Hill. 
It Takes a Village

Cornbleth, C., \& Ellsworth, J. (1994). Teachers in teacher education: Clinical faculty roles and relationships. American Educational Research Journal, 31(1), 49-70.

Cowen-Fletcher, J. (1994). It Takes a Village. New York City, NY: Scholastic Press.

Cronbach, L. J., \& Furby, L. (1970). How should we measure "change” - Or should we? Psychological Bulletin, 74, 68-80.

Darling-Hammond, L. (2000). How teacher education matters. Journal of Teacher Education, 51(3), 166-73.

Darling-Hammond, L. (2001). The challenge of staffing our schools, Educational Leadership. 58(8), 12-17.

Darling-Hammond, L. (2009, February). Teacher education and the American future. Charles W. Hunt Lecture. Presented at the annual meeting of the American Association of Colleges for Teacher Education, Chicago, IL.

Eisenhart, M., Borko, H., Underhill, R., Brown, C., Jones, D., \& Agard, P. (1993). Conceptual knowledge falls through the cracks: Complexities of learning to teach mathematics for understanding. Journal for Research in Mathematics Education, 24, 4-40.

Ellis, P. D. (2010). The Essential Guide to Effect Sizes: An Introduction to Statistical Power, Meta-Analysis and the Interpretation of Research Results. United Kingdom: Cambridge University Press.

Feiman-Nemser, S. (2001). From preparation to practice: Designing a continuum to strengthen and sustain teaching. Teachers College Record, 103(6), 1013-1055.

Gee, J. P. (1999). An introduction to discourse analysis: Theory and method. London, England: Routledge. 
It Takes a Village

Gee, J. P. (2001). Literacy, discourse, and linguistics: Introduction. In E. Cushman, E.R. Kintgen, B. Kroll, \& M. Rose (Eds.), Literacy: A critical sourcebook (pp. 525544). Boston, MA: Bedford/St. Martin’s.

Guyton, E., \& McIntrye, D.J. (1990). Student teaching and school experiences. In W.R. Houston (Ed.), Handbook of research on teacher education (pp. 514-534). New York: Macmillan.

Hall, S. (2000). Foreword. In D. A. Yon, Elusive Culture: Schooling, Race, and Identity in Global Times. Albany, NY: State University of New York Press.

Hargreaves, A. \& Fullan, M. (2000). Mentoring in the new millennium. Theory into Practice. 39(1) (50-56)

Hollingsworth, S. (1989). Prior beliefs and cognitive change in learning to teach. American Educational Research Journal, 26, 160-189.

Howard, G. S., Ralph, K. M., Gulanick, N. A., Maxwell, S. E., Nance, D., \& Gerber, S. (1979). Internal invalidity in pretest- posttest self-report evaluation and a re evaluation of retrospective pretests. Applied Psychological Measurement, 3, 1-23.

Ma, L. (1999). Knowing and teaching elementary mathematics: Teachers' understanding of fundamental mathematics in China and the United States. Mahwah, NJ: Lawrence Erlbaum.

McMillan, J. H. \& Schumacher, S. (2001). Research in education: a conceptual introduction. New York City, New York: Longman.

McNeal, B. (2001). Making sense of mathematics teaching in real contexts. In T. Wood, B. S. Nelson, \& J. Warfield (Eds.), Beyond classical pedagogy: Teaching elementary school mathematics (pp. 209-238). Mahwah, NJ: Erlbaum. 
It Takes a Village

National Council of Teachers of Mathematics. (2000). Principles and standards for school mathematics. Reston, VA: Author.

Ross, J. A., McDougall, D., Hogaboam-Gray, A., \& LeSage, A. (2003). A survey measuring elementary teachers' implementation of standards-based mathematics teaching. Journal for Research in Mathematics Education, 34(4), 344-363.

Sandholtz, J. H., \& Finan, E. C. (1998). Blurring the boundaries to promote school university partnerships. Journal of Teacher Education, 49(1), 13-25.

Sumara, D. J., \& Luce-Kapler, R. (1996). (Un)becoming a teacher: Negotiating identities while learning to teach. Canadian Journal of Education, 21(1), 65-83.

Statistical Package for Social Sciences for Mac. (2008). (Version 16.0) [Computer software]. Chicago, IL: SPSS, Inc.

Tabachnick, B. R., Popkewitz, T. S., \& Zeichner, K. M. (1979-1980). Teacher education and the professional perspectives of student teachers. Interchange, 10(4), 12-29.

Vacc, N. N., \& Bright, G. W. (1999). Elementary preservice teachers' changing beliefs and instructional use of children's mathematical thinking. Journal for Research in Mathematics Education, 30, 89-110.

Wood, T., \& Turner-Vorbeck, T. (2001). Extending the conception of mathematics teaching. In T. Wood, B. S. Nelson, \& J. Warfield (Eds.), Beyond classical pedagogy: Teaching elementary school mathematics (pp. 185-207). Mahwah, NJ: Erlbaum.

Zeichner, K. (2010). Rethinking the connections between campus courses and field experiences in college- and university-based teacher education. Journal of Teacher Education, 61(1-2), 89-99. 
It Takes a Village

Appendix

Field Practicum Survey

Mathematics 
It Takes a Village

Section 1. To what extent do you agree that these statements characterize the approach you will take in teaching mathematics in your own classroom?

1.1 I will use math problems that can be solved in many different ways. strongly disagree disagree disagree somewhat agree somewhat agree strongly agree

1.2 I will regularly have my students work through real-life math problems that are of interest to them.

strongly disagree disagree disagree somewhat agree somewhat agree strongly agree

1.3 When two students solve the same math problem correctly using two different strategies I will have them share the steps they went through with each other.

strongly disagree disagree disagree somewhat agree somewhat agree strongly agree

1.4 I will tend to integrate multiple strands of mathematics (number, geometry, measurement, etc.) within a single unit.

strongly disagree disagree disagree somewhat agree somewhat agree strongly agree

1.5 I will often learn from my students during math time because my students come up with ingenious ways of solving problems that I have never thought of.

strongly disagree disagree disagree somewhat agree somewhat agree strongly agree

1.6 It is not very productive for students to work together during math time.

strongly disagree disagree disagree somewhat agree somewhat agree strongly agree

1.7 Every child in my room should feel that mathematics is something he/she can do.

strongly disagree disagree disagree somewhat agree somewhat agree strongly agree

1.8 I will integrate math assessment into most math activities.

strongly disagree disagree disagree somewhat agree somewhat agree strongly agree

1.9 In my class, students learn math best when they can work together to discover mathematical ideas.

strongly disagree disagree disagree somewhat agree somewhat agree strongly agree

1.10 I will encourage students to use manipulatives to explain their mathematical ideas to other students.

strongly disagree disagree disagree somewhat agree somewhat agree strongly agree 
It Takes a Village

1.11 When students are working on math problems, I will put more emphasis on getting the correct answer than on the process followed.

strongly disagree disagree disagree somewhat agree somewhat agree strongly agree

1.12 Creating rubrics for math is a worthwhile assessment strategy.

strongly disagree disagree disagree somewhat agree somewhat agree strongly agree

1.13 In my class it will be just as important for students to learn data management and probability as it is to learn multiplication facts.

strongly disagree disagree disagree somewhat agree somewhat agree strongly agree

1.14 I won't necessarily answer students' math questions but rather let them puzzle things out for themselves.

strongly disagree disagree disagree somewhat agree somewhat agree strongly agree

1.15 A lot of things in math must simply be accepted as true and remembered.

strongly disagree disagree disagree somewhat agree somewhat agree strongly agree

1.16 I will encourage my students to master basic mathematical operations before they tackle complex problems.

strongly disagree disagree disagree somewhat agree somewhat agree strongly agree

1.17 I will teach students how to explain their mathematical ideas.

strongly disagree disagree disagree somewhat agree somewhat agree strongly agree

1.18 Using computers to solve math problems distracts students from learning basic math skills.

strongly disagree disagree disagree somewhat agree somewhat agree strongly agree

1.19 If students use calculators they won't master the basic math skills they need to know.

strongly disagree disagree disagree somewhat agree somewhat agree strongly agree

1.20 You have to study math for a long time before you see how useful it is.

strongly disagree disagree disagree somewhat agree somewhat agree strongly agree

Comments about your responses to any of the above items (optional): 
It Takes a Village

Section 2. NOW THINK BACK BEFORE YOUR PRACTICUM. To what extent do you agree that these statements characterize the approach you would take to teaching mathematics based on how you felt before your practicum.

2.1 I will use math problems that can be solved in many different ways.

strongly disagree disagree disagree somewhat agree somewhat agree strongly agree

2.2 I will regularly have my students work through real-life math problems that are of interest to them.

strongly disagree disagree disagree somewhat agree somewhat agree strongly agree

2.3 When two students solve the same math problem correctly using two different strategies I will have them share the steps they went through with each other.

strongly disagree disagree disagree somewhat agree somewhat agree strongly agree

2.4 I will tend to integrate multiple strands of mathematics (number, geometry, measurement, etc.) within a single unit.

strongly disagree disagree disagree somewhat agree somewhat agree strongly agree

2.5 I will often learn from my students during math time because my students come up with ingenious ways of solving problems that I have never thought of.

strongly disagree disagree disagree somewhat agree somewhat agree strongly agree

2.6 It is not very productive for students to work together during math time.

strongly disagree disagree disagree somewhat agree somewhat agree strongly agree

2.7 Every child in my room should feel that mathematics is something he/she can do.

strongly disagree disagree disagree somewhat agree somewhat agree strongly agree

2.8 I will integrate math assessment into most math activities.

strongly disagree disagree disagree somewhat agree somewhat agree strongly agree

2.9 In my class, students learn math best when they can work together to discover mathematical ideas.

strongly disagree disagree disagree somewhat agree somewhat agree strongly agree

2.10 I will encourage students to use manipulatives to explain their mathematical ideas to other students.

strongly disagree disagree disagree somewhat agree somewhat agree strongly agree 
It Takes a Village

2.11 When students are working on math problems, I will put more emphasis on getting the correct answer than on the process followed.

strongly disagree disagree disagree somewhat agree somewhat agree strongly agree

2.12 Creating rubrics for math is a worthwhile assessment strategy.

strongly disagree disagree disagree somewhat agree somewhat agree strongly agree

2.13 In my class it will be just as important for students to learn data management and probability as it is to learn multiplication facts.

strongly disagree disagree disagree somewhat agree somewhat agree strongly agree

2.14 I won't necessarily answer students' math questions but rather let them puzzle things out for themselves.

strongly disagree disagree disagree somewhat agree somewhat agree strongly agree

2.15 A lot of things in math must simply be accepted as true and remembered.

strongly disagree disagree disagree somewhat agree somewhat agree strongly agree

2.16 I will encourage my students to master basic mathematical operations before they tackle complex problems.

strongly disagree disagree disagree somewhat agree somewhat agree strongly agree

2.17 I will teach students how to explain their mathematical ideas.

strongly disagree disagree disagree somewhat agree somewhat agree strongly agree

2.18 Using computers to solve math problems distracts students from learning basic math skills.

strongly disagree disagree disagree somewhat agree somewhat agree strongly agree

2.19 If students use calculators they won't master the basic math skills they need to know.

strongly disagree disagree disagree somewhat agree somewhat agree strongly agree

2.20 You have to study math for a long time before you see how useful it is.

strongly disagree disagree disagree somewhat agree somewhat agree strongly agree

Comments about your responses to any of the above items (optional): 
It Takes a Village

Section 3. Based on your observations of his or her teaching, to what extent do you think your mentor teacher would agree or disagree with the following statements?

3.1 Students should have access to multiple strands of mathematical knowledge, not just numbers and operations.

strongly disagree disagree disagree somewhat agree somewhat agree strongly agree

3.2 Students should be invited to solve complex, open-ended problems embedded in real-life contexts.

strongly disagree disagree disagree somewhat agree somewhat agree strongly agree

3.3 Students are capable of discovering important mathematical ideas and solving mathematical problems without direct instruction from the teacher.

strongly disagree disagree disagree somewhat agree somewhat agree strongly agree

3.4 The teacher's role in the mathematical classroom is that of co-learner and creator of mathematical community rather than sole knowledge expert.

strongly disagree disagree disagree somewhat agree somewhat agree strongly agree

3.5 Students should have ready access to various mathematical tools and manipulatives to aid their problem-solving activity.

strongly disagree disagree disagree somewhat agree somewhat agree strongly agree

3.6 Student-to-student interaction will facilitate the learning of mathematics.

strongly disagree disagree disagree somewhat agree somewhat agree strongly agree

3.7 Assessment of student learning should integrate with instruction, allow for multiple levels of performance, and be relevant to students' lives.

strongly disagree disagree disagree somewhat agree somewhat agree strongly agree

3.8 Mathematics is a growing, ever-developing body of knowledge.

strongly disagree disagree disagree somewhat agree somewhat agree strongly agree

3.9 Mathematics is a subject for which teachers should foster students' selfconfidence.

strongly disagree disagree disagree somewhat agree somewhat agree strongly agree

Comments about your responses to any of the above items (optional): 
It Takes a Village

$\underline{\text { Section } 4 .}$ To what extent do you think your $\underline{\text { CFA }}$ would agree or disagree with these?

4.1 Students should have access to multiple strands of mathematical knowledge, not just numbers and operations.

strongly disagree disagree disagree somewhat agree somewhat agree strongly agree

4.2 Students should be invited to solve complex, open-ended problems embedded in real-life contexts.

strongly disagree disagree disagree somewhat agree somewhat agree strongly agree

4.4 Students are capable of discovering important mathematical ideas and solving mathematical problems without direct instruction from the teacher.

strongly disagree disagree disagree somewhat agree somewhat agree strongly agree

4.4 The teacher's role in the mathematical classroom is that of co-learner and creator of mathematical community rather than sole knowledge expert.

strongly disagree disagree disagree somewhat agree somewhat agree strongly agree

4.5 Students should have ready access to various mathematical tools and manipulatives to aid their problem-solving activity.

strongly disagree disagree disagree somewhat agree somewhat agree strongly agree

4.6 Student-to-student interaction will facilitate the learning of mathematics.

strongly disagree disagree disagree somewhat agree somewhat agree strongly agree

4.7 Assessment of student learning should integrate with instruction, allow for multiple levels of performance, and be relevant to students' lives.

strongly disagree disagree disagree somewhat agree somewhat agree strongly agree

4.8 Mathematics is a growing, ever-developing body of knowledge.

strongly disagree disagree disagree somewhat agree somewhat agree strongly agree

4.9 Math is a subject for which teachers should foster students' self-confidence.

strongly disagree disagree disagree somewhat agree somewhat agree strongly agree

4.10 How many times did your CFA observe your mathematics teaching?

None once twice more than twice

Comments about your responses to any of the above items (optional): 
It Takes a Village

Section 5. To what extent do you think your school facilitator would agree ... ?

5.1 Students should have access to multiple strands of mathematical knowledge, not just numbers and operations.

strongly disagree disagree disagree somewhat agree somewhat agree strongly agree

5.2 Students should be invited to solve complex, open-ended problems embedded in real-life contexts.

strongly disagree disagree disagree somewhat agree somewhat agree strongly agree

5.3 Students are capable of discovering important mathematical ideas and solving mathematical problems without direct instruction from the teacher.

strongly disagree disagree disagree somewhat agree somewhat agree strongly agree

5.4 The teacher's role in the mathematical classroom is that of co-learner and creator of mathematical community rather than sole knowledge expert.

strongly disagree disagree disagree somewhat agree somewhat agree strongly agree

5.5 Students should have ready access to various mathematical tools and manipulatives to aid their problem-solving activity.

strongly disagree disagree disagree somewhat agree somewhat agree strongly agree

5.6 Student-to-student interaction will facilitate the learning of mathematics.

strongly disagree disagree disagree somewhat agree somewhat agree strongly agree

5.7 Assessment of student learning should integrate with instruction, allow for multiple levels of performance, and be relevant to students' lives.

strongly disagree disagree disagree somewhat agree somewhat agree strongly agree

5.8 Mathematics is a growing, ever-developing body of knowledge.

strongly disagree disagree disagree somewhat agree somewhat agree strongly agree

5.9 Math is a subject for which teachers should foster students' self-confidence.

strongly disagree disagree disagree somewhat agree somewhat agree strongly agree

5.10 How many times did the school facilitator observe your math teaching?

None once twice more than twice

Comments about your responses to any of the above items (optional): 
It Takes a Village

Section 6. When it comes to your mathematics experiences during the practicum, to what extent did the mentor teacher support you in the following ways?

6.1 Guide you toward lesson resources to help you plan your lessons never seldom sometimes frequently consistently

6.2 Plan with you prior to your assisting and teaching experiences never seldom sometimes frequently consistently

6.3 Provide appropriate guidance for you when planning never seldom sometimes frequently consistently

6.4 Help you to feel welcome in his or her classroom never seldom sometimes frequently consistently

6.5 Provide appropriate feedback after your assisting and teaching experiences never seldom sometimes frequently consistently

6.6 Provide opportunities for you to apply the methods you were learning in the methods class

never seldom fometimes frently consistently

Comments about your responses to any of the above items (optional): 